Research Article

\title{
Effect of Blending Degree between Virgin and Aged Binder on Pavement Performance of Recycled Asphalt Mixture with High RAP Content
}

\author{
Ying Xu $\mathbb{D}^{1},{ }^{1,2}$ Zhijing Chou, ${ }^{1}$ Yunze Li, ${ }^{1}$ Jie Ji $\mathbb{D}^{1,2}$ and Shi-fa $X u^{1,2}$ \\ ${ }^{1}$ School of Civil Engineering and Transportation, Beijing University of Civil Engineering and Architecture, Beijing 100044, China \\ ${ }^{2}$ Beijing Urban Transportation Infrastructure Engineering Technology Research Center, Beijing 100044, China \\ Correspondence should be addressed to Ying Xu; caacxuying@126.com
}

Received 29 March 2019; Revised 31 July 2019; Accepted 4 September 2019; Published 25 September 2019

Guest Editor: Hassan Baaj

Copyright (C) 2019 Ying Xu et al. This is an open access article distributed under the Creative Commons Attribution License, which permits unrestricted use, distribution, and reproduction in any medium, provided the original work is properly cited.

\begin{abstract}
In this study, the influence of the blending degree between virgin and aged binder on the pavement performance of hot-mix recycled asphalt mixture (HMRAM) with high RAP content is analyzed. The aggregate gradation of AC-16 was selected. The RAP contents were 30,40 , and $50 \%$. HMRAMs with different degrees of blending (DOBs) were prepared by changing the mixing temperature (150, 165 , and $180^{\circ} \mathrm{C}$ ) without the occurrence of excessive aging for asphalt binders. An improved Hirsch dynamic modulus prediction model was then used to quantitatively characterize the DOB of HMRAM. Finally, the high-temperature, low-temperature, moisture stability, and fatigue resistance performance of HMRAM were tested and the effect of the DOB between the virgin and aged asphalt binder on the pavement performance was analyzed. The results showed that the DOB between the virgin and aged asphalt binder cannot reach $100 \%$ at the three mixing temperatures for HMRAM with 30, 40, and 50\% RAP contents, which is inconsistent with the assumption of complete blending in China's specification. The dynamic stability of the mixture gradually decreases with the increased DOB for HMRAM with a high RAP content, while the moisture stability, low-temperature, and fatigue resistance performance are continuously improved. This means that with the increase in DOB in the stage of open to traffic, meeting high-temperature performance criteria at the design stage may become unsatisfactory for HMRAM. The moisture stability, low-temperature performance, and fatigue resistance performances of HMRAM measured at the design stage were reasonable and conservative. The change in DOB significantly affects the content and properties of total free binder in HMRAM, affecting pavement performance. The content and physical properties of the RAP aggregate also have a significant impact on pavement performance.
\end{abstract}

\section{Introduction}

More transportation agencies are moving toward the increased use of reclaimed asphalt pavement (RAP) due to the increasing demand for environment-friendly paving mixtures and the significant increase in the costs of raw asphalt binder [1]. In the production and mixing process of the hotmix recycled asphalt mixture (HMRAM), the aged binder coated outside the old aggregate in the RAP will be blended with a rejuvenator and virgin binder. Based on the mobilized proportion of the RAP binder, the degrees of blending (DOB) between the RAP binder and virgin binder are classified into no-blending ("black rock"), partial blending, and complete blending states [2].
At present, HMRAMs are mostly designed based on the assumption of a complete blending state. Recent studies have shown that under normal production conditions when the RAP content is less than $30 \%$, the DOB for the RAP approaches $100 \%$ [2], which conforms to the assumption of the current design specifications. However, for HMRAM with a high RAP content ( $>30 \%)$, only the partial aged binders in the RAP are blended with the virgin binders, which results in inconsistency with the design assumption. Therefore, the DOB quantification between the RAP binder and virgin binder is the key issue for the design of HMRAM with a high RAP content.

In previous research studies, the extents of the RAP binder mobilization and RAP mixture blending have been characterized using chemical and mechanical approaches. In 
the chemical approach, after HMRAMs are stage extracted, gel permeation chromatography (GPC), Fourier transform infrared (FTIR) spectroscopy, etc., are used to evaluate the difference between the RAP binders in different layers [3-5]. In the mechanical approach, the amount of blending is indirectly determined by comparing the rheological properties of HMRAM and ideal mixtures in which the extracted RAP binder is already blended with the virgin bitumen prior to mixing [6-8]. The DOB can be characterized by comparing the dynamic modulus of the mixtures to that of those predicted using the Hirsch model or Witczak model based on the complex modulus of the recovered binder $[9,10]$. Although the mechanical approach is considered faulty, it is still one of those most commonly used.

Since the RAP binder is usually stiffer than the virgin binder [11], the extent of RAP binder mobilization and RAP mixture blending has a significant impact on the properties of the binder and HMRAM $[12,13]$. Carpenter and Wolosick [14] found that the DOB of the recycled asphalt mixture after compaction continues to gradually increase, which results in the decrease of the resilience modulus and rutting resistance of the asphalt mixture. The research studies of Noureldin and Wood also validated these results [15]. McDaniel et al. [16] considered that the DOB has no significant effect on the stiffness and deformation resistance of the mixture at $10 \%$ RAP content. However, for HMRAM with a high RAP content of $40 \%$, a lower DOB resulted in a lower stiffness of the mixture and poor deformation resistance. Stephens et al. [17] found that prolonging the preheating of the RAP resulted in a higher DOB, which increased the unconfined compressive strength and splitting strength of the recycled asphalt mixture. Coffey et al. [18] measured the DOB of three kinds of HMRAM with an RAP content of $25 \%$. All the DOBs obtained are higher than $85 \%$. Changes in the DOB have minimal effect on the fatigue and rutting resistance of the mixtures.

The mixing conditions have a significant effect on the DOB of HMRAM. By investigating the effects of the production stages, including the RAP binder transfer, mechanical blending, and diffusion, on the blending of RAP and virgin binders and the mechanical properties of RAP mixtures, Zhang and Muhunthan et al. [19] found that diffusion is the stage that affects the rheological and fracture properties of RAP mixtures the most. They also found that thorough mechanical blending contributes to improvement in the ductility of high-percentage RAP mixtures. Kriz et al. [20] have proposed that production temperature and binder layer thickness in the mix has a significant impact in binder diffusion. As binder thickness in the mix is not uniform, there may be regions where a binder layer is thicker than expected, which results in partial blending status between virgin and aged binder after production and placement of mixture. While the diffusion continues at the ambient temperature, it can take months or even years for blending completion. Rad et al. [21] also proposed that the mixing temperature should be increased in the production stage to promote complete blending between the virgin and aged binders. Bowers [22] studied the influencing factors of the blending state between the virgin and aged binders, demonstrating that the temperature of the mixture had a significant effect on the blending state between the virgin and aged binders. They found that the higher the temperature was, the faster the diffusion rate between the virgin and aged binders was. Based on the literature above, the mixing temperature has been found to significantly affect the diffusion and DOB between the virgin and aged binders in a recycled asphalt mixture.

In conclusion, many scholars have studied the influence of different RAP content on pavement performance [23-25]. It is considered that with an increasing RAP content, the hightemperature performance and tensile strength of the mixture will improve, but the fatigue performance and moisture stability will deteriorate. However, few studies have focused on the impact of single DOB changes on pavement performance for HMRAM with specific RAP content. As far as HMRAM with high RAP content (>30\%) is concerned, complete blending status is difficult for the DOB to achieve at the end of construction, changing gradually after construction [2]. How does this change affect the pavement performance after construction? What is the best means of dealing with this impact in the HMRAM design stage? Additional research is required.

Therefore, the objective of this research is to evaluate the relationship between the DOB and pavement performance, such as the high-temperature, low-temperature, moisture stability, and fatigue resistance performances for HMRAM with high RAP content. Firstly, HMRAMs with three different RAP contents are prepared under different mixing temperature. Secondly, the DOB of HMRAM is quantitatively characterized using the mechanical method based on the improved Hirsch dynamic modulus prediction model. Thirdly, the pavement performances of HMRAMs are tested. Finally, the relationship between the pavement performance and DOB of HMRAM are analyzed.

\section{Materials and Methods}

\subsection{Raw Materials}

2.1.1. RAP Material. The RAP material selected in this study comes from the asphalt surface material milled from a municipal road in Beijing. The RAP binder was extracted by the rotavapor method (T 0727-2011), and trichloroethylene was used as the solvent. Three indexes-ductility at $15^{\circ} \mathrm{C}$, penetration at $25^{\circ} \mathrm{C}$, and softening point for RAP binder-were tested and compared with the technical requirements of $\mathrm{AH}$ 70 asphalt binder. The test results are shown in Table 1.

According to the data in the table, the penetration and ductility of the RAP binder are $2.70 \mathrm{~mm}$ and $19.2 \mathrm{~cm}$, respectively, which are significantly lower than the technical standard of AH-70 asphalt binder, indicating that the aging degree of the RAP binder is very serious. The properties of extracted RAP aggregates are also tested. They are shown in Table 2.

2.1.2. Rejuvenator. In this study, the aged asphalt in RAP was regenerated by adding a rejuvenator, and a commercial rejuvenator was selected. The performance indexes are shown in Table 3. In the mixing process, the rejuvenator can be added in proportion after the dry mixing of RAP material and a new aggregate. 
TABLE 1: Properties of RAP binder.

\begin{tabular}{|c|c|c|c|c|c|c|}
\hline \multirow{2}{*}{ Indexes } & \multirow{2}{*}{ Units } & \multicolumn{3}{|c|}{ RAP binder samples } & \multirow{2}{*}{ Mean value } & \multirow{2}{*}{ AH-70 asphalt binder } \\
\hline & & A & $\mathrm{B}$ & $\mathrm{C}$ & & \\
\hline Ductility $\left(15^{\circ} \mathrm{C}, 5 \mathrm{~cm} / \mathrm{min}\right)$ & $\mathrm{cm}$ & 18.6 & 17.8 & 21.2 & 19.2 & $\geq 100$ \\
\hline Penetration $\left(25^{\circ} \mathrm{C}, 5 \mathrm{~s}, 100 \mathrm{~g}\right)$ & $0.1 \mathrm{~mm}$ & 26.8 & 25.9 & 28.4 & 27.0 & $60-80$ \\
\hline Softening point & ${ }^{\circ} \mathrm{C}$ & 59.1 & 58.5 & 58.6 & 58.7 & $\geq 46$ \\
\hline
\end{tabular}

TABle 2: Physical properties of the RAP aggregate.

\begin{tabular}{|c|c|c|c|c|c|}
\hline \multirow{2}{*}{ Indexes } & \multirow{2}{*}{ Units } & \multicolumn{3}{|c|}{ Particle size } & \multirow{2}{*}{ Test methods } \\
\hline & & $10 \sim 20 \mathrm{~mm}$ & $3 \sim 10 \mathrm{~mm}$ & $0.075 \sim 3 \mathrm{~mm}$ & \\
\hline Crushing value & $\%$ & 17.6 & - & - & T 0316 \\
\hline Los Angeles wear loss & $\%$ & 19.4 & 19.4 & - & Т 0317 \\
\hline Polished value & - & 38 & - & - & Т 0321 \\
\hline Apparent density & $\mathrm{g} / \mathrm{cm}^{3}$ & 2.721 & 2.715 & 2.708 & Т 0304 \\
\hline Water absorption & $\%$ & 0.3 & 0.4 & 0.6 & Т 0304 \\
\hline Adhesion to asphalt & Grade & 5 & - & - & T 0616 \\
\hline
\end{tabular}

TABLE 3: The properties of rejuvenator.

\begin{tabular}{lccccc}
\hline Indexes & $\begin{array}{c}\text { Viscosity }\left(60^{\circ} \mathrm{C}\right) / \\
\left(10^{-3} \mathrm{~Pa} \cdot \mathrm{s}\right)\end{array}$ & Flash point $\left({ }^{\circ} \mathrm{C}\right)$ & $\begin{array}{c}\text { Rate of viscosity change } \\
\text { before and after TFOT }(\%)\end{array}$ & $\begin{array}{c}\text { Rate of mass change } \\
\text { before and after TFOT }(\%)\end{array}$ & $\begin{array}{c}\text { Density }\left(\mathrm{g} \cdot \mathrm{cm}^{-3}\right) \\
\text { Rejuvenator }\end{array}$ \\
364.2 & 256 & 2.55 & -3.29 \\
Requirements & $176 \sim 900$ & $\geq 220$ & $\leq 3$ & $\leq 4, \geq-4$ & 1.012 \\
\hline
\end{tabular}

Relevant specifications and studies have shown that the performance properties of recycled asphalt binder can be evaluated using penetration or a viscosity indicator. The general viscosity test temperature is $60^{\circ} \mathrm{C}$, owing to the high aging degree of the RAP binder. This study used the ductility at $15^{\circ} \mathrm{C}$, penetration at $25^{\circ} \mathrm{C}$, softening point, and viscosity at $135^{\circ} \mathrm{C}$ as the indexes to determine the adding content of the rejuvenator. The performance properties of the regenerated RAP binder should meet the technical requirements of the AH-70 asphalt binder.

The determining method of the rejuvenator content is explained by 30\% RAP content. According to application experience, the adding content of the rejuvenator is suggested as $3 \%, 4 \%, 5 \%$, and $6 \%$ (the mass ratio of the rejuvenator to the RAP binder). The performance properties of the regenerated RAP binder after adding different rejuvenator content are shown in Table 4.

According to the data in Table 4, with the increase in the rejuvenator content, the penetration and ductility of the regenerated RAP binder shows an upward trend, while the softening point and viscosity at $135^{\circ} \mathrm{C}$ decrease gradually. When the mass ratio of the rejuvenator to RAP binder is $5 \%$, all the performance index values of the regenerated RAP binder meet the technical requirements of AH-70 asphalt binder. Therefore, an adding content of $5 \%$ of rejuvenator is used.

2.1.3. Virgin Aggregate and Binder. In this study, the aged binder in RAP is regenerated by adding a rejuvenator. The insufficient amount of total asphalt binder is supplemented with a virgin $\mathrm{AH}-70$ asphalt binder. The virgin aggregate and mineral filler are limestone. The properties are shown in Tables 5 7.

\subsubsection{Mix Design of Recycled Mixture with High RAP Content}

(1) Gradation Design of HMRAM. In this study, three high RAP contents of $30 \%, 40 \%$, and $50 \%$ were selected, which is the ratio of the RAP materials to the total HMRAM mass. The selected gradation is AC- 16 . To decrease the variability of the RAP material, RAP materials were divided into four grades: $0 \sim 1.18 \mathrm{~mm}, 1.18 \sim 4.75 \mathrm{~mm}, 4.75 \sim 13.2 \mathrm{~mm}$, and $13.2 \sim 16 \mathrm{~mm}$. RAP material that is too fine will significantly affect the performance of HMRAM and make difficult meeting the specification requirements of AC-16 for the synthetic gradation. Therefore, RAP materials of $0 \sim 1.18 \mathrm{~mm}$ grade has been removed. The remaining three grades of the RAP materials are mixed according to the mass ratio of $10 \%, 60 \%$, and $30 \%$. In determining the ratio of the RAP and new aggregate, the RAP is not added as a "black stone," instead the old aggregates in the RAP after extraction are compounded with the virgin aggregate to ensure that the synthetic gradation of HMRAM meets the requirements of AC-16. The three grades of mixed RAP materials are extracted, and the content of RAP binder is tested at $4.4 \%$. The gradation curve is shown in Figure 1.

(2) Choice of Mixing Method. Based on the past research studies, it was found that the mixing temperature has the most significant influence on the DOB [26]. Therefore, to prepare HMRAM with different DOBs, the mixing temperatures with different RAP contents are selected as $150^{\circ} \mathrm{C}$, $165^{\circ} \mathrm{C}$, and $180^{\circ} \mathrm{C}$. HMRAM with a complete blending state is also prepared by mixing the virgin binder and aggregate with a complete separating RAP binder and old aggregate using the RAP extraction method. All other mixing 
TABLE 4: Performance properties of regenerated RAP binder.

\begin{tabular}{lccccccc}
\hline \multirow{2}{*}{ Indexes } & \multirow{2}{*}{ Units } & \multicolumn{4}{c}{ Adding content of rejuvenator } & \multirow{2}{*}{ Technical requirements of AH-70 asphalt binder } \\
& & 0 & $3 \%$ & $4 \%$ & $5 \%$ & $6 \%$ & - \\
Viscosity $\left(25^{\circ} \mathrm{C}\right)$ & $\mathrm{Pa} \cdot \mathrm{s}$ & 1.362 & 0.953 & 0.696 & 0.527 & 0.263 & $\geq 100$ \\
Ductility $\left(15^{\circ} \mathrm{C}, 5 \mathrm{~cm} / \mathrm{min}\right)$ & $\mathrm{Cm}$ & 19.2 & 53.8 & 80.5 & 143.2 & 193.5 & $60 \sim 80$ \\
Penetration $\left(25^{\circ} \mathrm{C}, 5 \mathrm{~s}, 100 \mathrm{~g}\right)$ & $0.1 \mathrm{~mm}$ & 27.2 & 49.5 & 56.3 & 69.5 & 76.3 & $\geq 46$ \\
Softening point & ${ }^{\circ} \mathrm{C}$ & 58.7 & 54.6 & 51.3 & 48.7 & 44.2 & \\
\hline
\end{tabular}

TABLE 5: Physical properties of the virgin aggregate.

\begin{tabular}{|c|c|c|c|c|c|c|}
\hline \multirow{2}{*}{ Indexes } & \multirow{2}{*}{ Units } & \multirow{2}{*}{ Norms requirements } & \multicolumn{3}{|c|}{ Particle size } & \multirow{2}{*}{ Test methods } \\
\hline & & & $10 \sim 20 \mathrm{~mm}$ & $3 \sim 10 \mathrm{~mm}$ & $0.075 \sim 3 \mathrm{~mm}$ & \\
\hline Crushing value & $\%$ & $\leq 26$ & 19.8 & - & - & T 0316 \\
\hline Los Angeles wear loss & $\%$ & $\leq 28$ & 17.5 & 17.5 & - & Т 0317 \\
\hline Polished value & - & $\geq 40$ & 42 & - & - & Т 0321 \\
\hline Apparent density & $\mathrm{g} / \mathrm{cm}^{3}$ & - & 2.736 & 2.731 & 2.726 & Т 0304 \\
\hline Water absorption & $\%$ & $\leq 2.0$ & 0.5 & 0.4 & 0.3 & Т 0304 \\
\hline Adhesion to asphalt & Grade & $\geq 5$ & 5 & - & - & Т 0616 \\
\hline
\end{tabular}

TABLE 6: The properties of mineral filler.

\begin{tabular}{|c|c|c|c|c|c|}
\hline \multicolumn{2}{|l|}{ Indexes } & Units & Standard & Test results & Test methods \\
\hline \multicolumn{2}{|l|}{ Apparent density } & $\mathrm{g} / \mathrm{cm}^{3}$ & $\geq 2.5$ & 2.697 & T 0352 \\
\hline \multicolumn{2}{|l|}{ Moisture content } & $\%$ & $\leq 1$ & 0.3 & Т 0103 \\
\hline & $<0.6 \mathrm{~mm}$ & $\%$ & 100 & 100.0 & \\
\hline \multirow[t]{2}{*}{ Particle size range } & $<0.15 \mathrm{~mm}$ & $\%$ & $90 \sim 100$ & 98.0 & Т 0351 \\
\hline & $<0.075 \mathrm{~mm}$ & $\%$ & $75 \sim 100$ & 95.0 & \\
\hline \multicolumn{2}{|c|}{ Hydrophilicity coefficient } & - & $<1.0$ & 0.76 & Т 0353 \\
\hline
\end{tabular}

TABLE 7: The properties of AH-70 virgin binder.

\begin{tabular}{|c|c|c|c|c|}
\hline \multicolumn{2}{|l|}{ Indexes } & Units & Test results & Test methods \\
\hline \multicolumn{2}{|c|}{ Penetration $\left(25^{\circ} \mathrm{C}, 5 \mathrm{~s}, 100 \mathrm{~g}\right)$} & $0.1 \mathrm{~mm}$ & 69.9 & T 0604 \\
\hline \multicolumn{2}{|c|}{ Softening point } & ${ }^{\circ} \mathrm{C}$ & 48.6 & T 0606 \\
\hline \multicolumn{2}{|c|}{ Ductility $\left(15^{\circ} \mathrm{C}, 5 \mathrm{~cm} / \mathrm{min}\right)$} & $\mathrm{cm}$ & 149 & Т 0605 \\
\hline \multicolumn{2}{|l|}{ Density $\left(15^{\circ} \mathrm{C}\right)$} & $\mathrm{g} / \mathrm{cm}^{3}$ & 1.031 & Т 0603 \\
\hline \multirow{3}{*}{ Residue after RTFOT } & Quality loss & $\%$ & 0.3 & Т 0609 \\
\hline & Penetration ratio & $\%$ & 70.4 & Т 0604 \\
\hline & Ductility at $15^{\circ} \mathrm{C}$ & $\mathrm{cm}$ & 48 & T 0605 \\
\hline
\end{tabular}

parameters are the same. The four mixing methods are summarized in Table 8.

To truly reflect the influence of thermal history of HMRAM samples on DOB, after 3 min of mixing, the HMRAM will be placed in an oven at $10^{\circ} \mathrm{C}$ lower than the mixing temperature for $1.5 \mathrm{~h}$ to simulate the diffusion process between the virgin and aged binder during the storage and transportation stages. The storage temperature is $10^{\circ} \mathrm{C}$ lower than the mixing temperature because the temperature of the mixture during storage and transportation is generally $10-15^{\circ} \mathrm{C}$ lower than the mixing temperature based on construction experience. After $1.5 \mathrm{~h}$ in a stored stage, the HMRAM were compacted and then placed in an oven at $20^{\circ} \mathrm{C}$ for $4 \mathrm{~h}$ at the cooling stage. The thermal history of the four mixing methods is shown in Figure 2.

Figure 2 shows that the thermal history of HMRAM samples can be divided into three stages, namely, mixing stage, storage and transportation stage, and placement and cooling stage. It should be emphasized that when the mixing temperature is different, not only will the diffusion rate between virgin and aged binder in the mixing stage be affected, but the different thermal history of HMRAM samples in the storage and transportation stage and placement and cooling stage will also have a significant impact on the diffusion rate. Therefore, the influence of the mixing temperature on DOB would be caused by the comprehensive thermal history difference in all three stages.

To evaluate whether different mixing temperatures will cause different degrees of aging of HMRAM, the penetration, softening point, and ductility of the extracted binder of HMRAM with $30 \%$ RAP content for the four mixing methods are tested. The test results are presented in Table 9. It shows that changing the mixing temperature does not cause significant differences in the degree of aging of the 


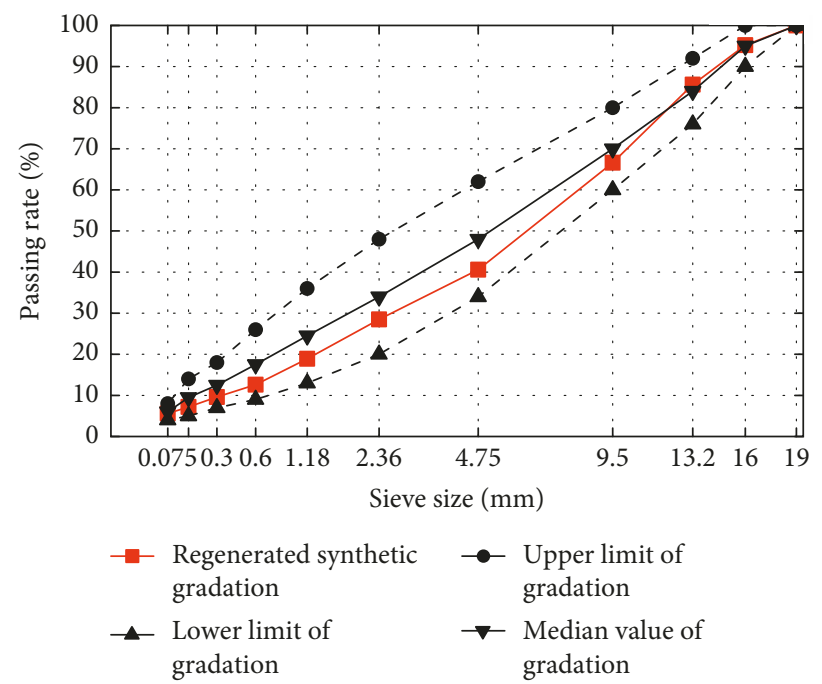

Figure 1: Synthetic gradation curve of AC-16.

TABle 8: Four mixing methods.

\begin{tabular}{|c|c|c|c|c|}
\hline Mixing method/mixing temperature & $\begin{array}{c}\text { Mixing method } 1 \\
150^{\circ} \mathrm{C}\end{array}$ & $\begin{array}{c}\text { Mixing method } 2 \\
165^{\circ} \mathrm{C}\end{array}$ & $\begin{array}{c}\text { Mixing method } 3 \\
180^{\circ} \mathrm{C}\end{array}$ & $\begin{array}{l}\text { Mixing method } 4(100 \% \text { DOB }) \\
165^{\circ} \mathrm{C}\end{array}$ \\
\hline RAP preheating time $(\mathrm{h})$ and temperature $\left({ }^{\circ} \mathrm{C}\right)$ & & & $2 ; 110$ & \\
\hline Heating temperature of virgin binder $\left({ }^{\circ} \mathrm{C}\right)$ & & & 165 & \\
\hline Heating temperature of virgin aggregate $\left({ }^{\circ} \mathrm{C}\right)$ & & & 180 & \\
\hline Mixing time ( $\mathrm{min})$ & & & 3 & \\
\hline Aggregate gradation & & & AC-16 & \\
\hline Binder content & & & Same & \\
\hline DOB state & Partial blending & Partial blending & Partial blending & Complete blending \\
\hline
\end{tabular}

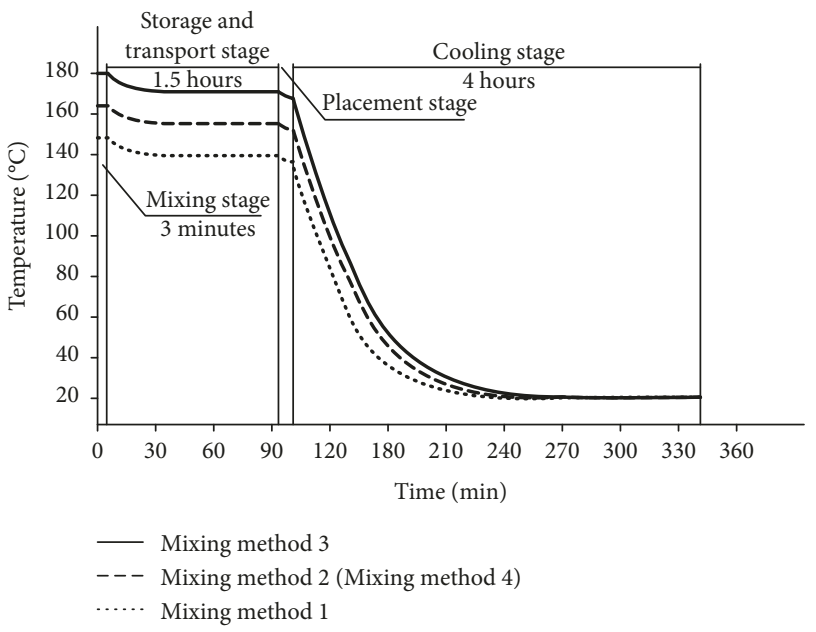

Figure 2: Thermal history of samples with different mixing method.

extracted binder. Therefore, the performance of HMRAM is only affected by the DOB.

(3) Optimum Binder Content. The Marshall Design method is used to determine the optimum binder content of HMRAM with the four mixing methods. To avoid the influence of a total binder content change on the pavement performance, we used the same total binder content for all the mixing methods in this study. Thus, only the DOB affects the composition of the effective HMRAM binder and its pavement performance. For HMRAM with mixing method 4 , the total binder content is determined as $4.4 \%$. Therefore, $4.4 \%$ is determined as the total binder content for all mixing modes. The virgin binder in HMRAM with different RAP contents is calculated using equation (1).

$$
P_{\mathrm{nb}}=P_{\mathrm{b}}-n \times P_{\mathrm{ab}}\left(1+P_{0}\right)
$$

where $P_{\mathrm{nb}}$-virgin binder content (\%) - the proportion of virgin binder in HMRAM; $P_{\mathrm{b}}$-total binder content $(\%)$ the proportion of the total content of virgin binder, RAP binder, and virgin binder in HMRAM; $P_{\mathrm{ab}}-$ RAP binder content (\%)-the proportion of RAP binder in RAP material; $n$-RAP material blending ratio-the proportion of RAP material in HMRAM; $P_{0}$-rejuvenator content (\%)-the mass ratio of rejuvenator to RAP binder.

Take $30 \%$ of RAP content as an example. The total binder content $P_{\mathrm{b}}$ (virgin binder plus RAP binder plus rejuvenator) is $4.4 \%, n$ is $30 \%$, and $\mathrm{P}_{\mathrm{ab}}$ is $4.4 \%$. Thus, the RAP binder content is $1.32 \%\left(n \times P_{\mathrm{ab}}=30 \% \times 4.4 \%=1.32 \%\right)$. The rejuvenator content $\mathrm{P}_{0}$ is $5 \%$. Thus, the rejuvenator content in HMRAM is $0.07 \%$ 
TABLE 9: Test results of the extracted HMRAM binder for the four mixing methods.

\begin{tabular}{|c|c|c|c|c|c|c|}
\hline Technical index & Units & $\begin{array}{l}\text { Mixing method } 1 \\
150^{\circ} \mathrm{C}\end{array}$ & $\begin{array}{c}\text { Mixing method } 2 \\
165^{\circ} \mathrm{C}\end{array}$ & $\begin{array}{c}\text { Mixing method } 3 \\
180^{\circ} \mathrm{C}\end{array}$ & $\begin{array}{l}\text { Mixing method } 4(100 \% \text { DOB }) \\
165^{\circ} \mathrm{C}\end{array}$ & Variance \\
\hline$\left(25^{\circ} \mathrm{C}, 5 \mathrm{~s}, 100 \mathrm{~g}\right)$ & $0.1 \mathrm{~mm}$ & 64.3 & 64.4 & 64.3 & 64.1 & 0.02 \\
\hline Softening point & ${ }^{\circ} \mathrm{C}$ & 49.3 & 49.3 & 49.4 & 49.6 & 0.02 \\
\hline Ductility $\left(15^{\circ} \mathrm{C}, 5 \mathrm{~cm} / \mathrm{min}\right)$ & $\mathrm{cm}$ & 133 & 134 & 133 & 134 & 0.33 \\
\hline
\end{tabular}

TABle 10: The binder composition in HMRAM.

\begin{tabular}{lcccc}
\hline RAP content (\%) & Total binder content (\%) & RAP binder (\%) & Virgin binder (\%) & Rejuvenator (\%) \\
\hline 30 & 4.4 & 1.32 & 3.01 & 0.07 \\
40 & 4.4 & 1.76 & 2.55 & 0.09 \\
50 & 4.4 & 2.20 & 2.09 & 0.11 \\
\hline
\end{tabular}

$\left(n \times \mathrm{P}_{\mathrm{ab}} \times P_{0}=30 \% \times 4.4 \% \times 5 \%=0.07 \%\right)$. Finally, the virgin binder content $\mathrm{P}_{\mathrm{nb}}$ is $3.01 \%(4.4 \%-1.32 \%-0.07 \%=3.01 \%)$. Similarly, the virgin binder content for $40 \%$ and $50 \%$ of RAP content can be obtained. The amounts of the RAP binder, virgin binder, and rejuvenator for different RAP contents are listed in Table 10.

\subsection{Test Method}

2.2.1. Characterization of the DOB between the RAP Binder and Virgin Binder. The aforementioned mechanical characterization method is used to determine the DOB of HMRAM [6-8]. However, in this method, the Hirsch model constants were determined based on assumptions and simplifications for conventional asphalt mixtures. Therefore, it may be inappropriate for the prediction of the dynamic modulus of HMRAM with a high RAP content. An improved Hirsch model proposed by Zhang et al. [27] is used in this study, which is defined in formulas (2) (5). The steps of the characterization are as follows:

$$
\begin{aligned}
\left|E^{*}\right|_{\text {mix }}= & P_{\mathrm{c}}\left[E_{\mathrm{a}}\left(1-\frac{\mathrm{VMA}}{100}\right)+\mid E_{\text {mastic }}^{*}\left(\frac{\mathrm{VFA} \times \mathrm{VMA}}{10000}\right)\right] \\
& +\left(1-P_{\mathrm{c}}\right)\left[\frac{1-(\mathrm{VMA} / 100)}{E_{\mathrm{a}}}+\frac{\mathrm{VMA}}{\mathrm{VFA}\left|E_{\text {mastic }}^{*}\right|}\right]^{-1}, \\
P_{\mathrm{c}}= & \frac{\left(20+\left(\left(\mathrm{VFA} \times\left|E_{\text {mastic }}^{*}\right|\right) / \mathrm{VMA}\right)\right)^{0.58}}{650+\left(\left(\mathrm{VFA} \times\left|E_{\text {mastic }}^{*}\right|\right) / \mathrm{VMA}\right)^{0.58},} \\
\frac{1}{\left|E_{\text {mastic }}^{*}\right|}= & \sqrt{\left(\frac{1}{2(1+v)\left|G_{\text {mastic }}^{*}\right| \cos \delta}+\frac{E_{2}}{E_{2}^{2}+\eta_{2}^{2} \omega^{2}}\right)^{2}+\left(\frac{1}{\eta_{1} \omega}+\frac{\eta_{2} \omega}{E_{2}^{2}+\eta_{2}^{2} \omega^{2}}\right)^{2},} \\
\frac{\eta_{2} \omega}{\eta_{1} \omega}+\frac{\mid G_{\text {mastic }}^{*}}{E_{2}^{2}+\eta_{2}^{2} \omega^{2}} & \frac{\sin \delta}{}
\end{aligned}
$$

where $E_{\mathrm{a}}$ is the elastic modulus of aggregates; $E_{2}$ is the elastic modulus of spring 2 in Burgers model; $\eta_{1}$ is the sticky pot 1 viscosity; $\eta_{2}$ is the sticky pot 2 viscosity; $\omega$ is the angular frequency; VMA is the voids in the mineral aggregate; VFA is the voids filled with asphalt; $\left|E_{\text {mastic }}^{*}\right|$ is the dynamic modulus of the mastic; and $\left|G_{\text {mastic }}^{*}\right|$ is the dynamic shear modulus of the mastic.

The usage of equations (2)-(5) is shown as follows. The angular frequency $\omega$ can be calculated by the formula $\omega=2 \pi f$, with the known frequency $f$. $\left|G_{\text {mastic }}^{*}\right|$ and phase angle $\delta$ of the mastic with known DOB can be measured by the DSR test. Then, the parameters $\eta_{1}, \eta_{2}$, and $E_{2}$ can be obtained through error minimization by equation (5), and $\left|E_{\text {mastic }}^{*}\right|$ can be calculated by equation (4). Then, the values of VMA and VFA of mixtures with known DOB are substituted into equation (3) to solve $P_{\mathrm{c}}$. Finally, all parameters are substituted in equation (2) to obtain the dynamic modulus of HMRAM, and the master curve of 
the dynamic modulus is drawn based on the dynamic modulus of HMRAM with different testing frequencies.

Step 1. Plotting of the master curve of the dynamic modulus of HMRAM

The dynamic modulus of HMRAM is tested by the uniaxial compression test (AASHTO TP 79-2013) method. The test temperatures are $20^{\circ} \mathrm{C}, 35^{\circ} \mathrm{C}$, and $50^{\circ} \mathrm{C}$. The loading frequencies are $0.1 \mathrm{~Hz}, 0.5 \mathrm{~Hz}, 1 \mathrm{~Hz}, 5 \mathrm{~Hz}, 10 \mathrm{~Hz}$, and $25 \mathrm{~Hz}$. The master curve of the dynamic modulus is plotted.

Step 2. Plotting of the theoretical master curve of the dynamic modulus of HMRAM with the DOB of $70,80,90$, and $100 \%$.

The mastic with DOB of $70,80,90$, and $100 \%$ is prepared. HMRAM with $30 \%$ RAP content is selected to illustrate the calculation process. The asphalt mastic with $100 \%$ DOB is prepared with $1.32 \%$ of completely activated RAP binder, $3.01 \%$ of virgin binder, $0.07 \%$ of rejuvenator, and $5.33 \%$ of mineral filler. The total free binder is defined as the sum of the activated RAP binder, virgin binder, and rejuvenator. When the $\mathrm{DOB}$ is $90 \%$, the content of activated RAP binder is $1.19 \%(1.32 \% \times 90 \%)$. The content of the virgin binder, rejuvenator, and mineral powder remains unchanged. Thus, the asphalt mastic with $90 \%$ DOB is prepared with $1.19 \%$ of activated aged binder in RAP, $3.01 \%$ of virgin binder, $0.07 \%$ of rejuvenator, and $5.33 \%$ of mineral power. Based on the same method, the asphalt mastic with $70 \%$ and $80 \%$ DOB is also prepared. The composition of the asphalt mastic with different DOBs is shown in Table 11.

The dynamic modulus of the mixture of $70,80,90$, and $100 \%$ is obtained as described in Section 2.2.1, and the dynamic modulus master curve is plotted at a reference temperature of $20^{\circ} \mathrm{C}$. The principal curve of the dynamic modulus is drawn as shown in Figure 3.

\section{Step 3. Determination of the DOB for HMRAM.}

The measured dynamic modulus master curve is compared with the theoretical master curve of HMRAM with the DOB of 70, 80, 90, and 100\%. As shown in Figure 3, the master curve with red color is measured based on the actual specimen and the other four gray predicted master curves with $70 \%, 80 \%, 90 \%$, and $100 \%$ DOB. Because the measured master curve is not parallel to the predicted master curve, the average value of the two interpolations for the actual principal curve at a minimum of $0.01 \mathrm{~Hz}$ and a maximum of $1000 \mathrm{~Hz}$ is adopted to characterize the DOB of the HMRAM specimen. Taking Figure 2 as an example, according to the interpolation relationship, $71 \%$ for end point $\mathrm{A}$ and $78 \%$ for end point $\mathrm{B}$ were obtained, and the average value of $74.5 \%$ was determined as the DOB of HMRAM. In the same way, the mixing degree of the recycled mixture with other RAP content can be obtained, as shown in Table 12.
2.2.2. Pavement Performance Test of HMRAM. According to the China specification (JTG E20-2011), the rutting test (T 0719-2011), the bending failure test (T 0715-2011) and the freeze-thaw splitting test (T 0729-2011) were used are used to test the high-temperature, low-temperature, and moisture stability performance of HMRAM, respectively. The rutting test (T 0719-2011) was originated from TRRL in Britain, which was tested at a temperature of $60^{\circ} \mathrm{C}$, a load of $0.7 \mathrm{MPa}$, and a rate of 42 times per minute. The low-temperature bending test ( $\mathrm{T}$ 0715-2011) used a wheelrolling method to form the rutting board, which is $300 \mathrm{~mm} \times 300 \mathrm{~mm} \times 50 \mathrm{~mm}$. Then, it was cut into a quadrangular beam with $250 \mathrm{~mm} \times 30 \mathrm{~mm} \times 35 \mathrm{~mm}$. Flexuraltensile strain at the failure of the beam specimen was tested under the testing condition of $-10^{\circ} \mathrm{C}$ and a loading rate of $50 \mathrm{~mm} / \mathrm{min}$ using UTM-25 equipment. The freeze-thaw splitting test ( $\mathrm{T}$ 0729-2000) originated from AASHTO T 283-98. The splitting strength ratio before and after the freeze-thaw cycle conditions is used to evaluate the moisture stability of the asphalt mixture. The four-point bending fatigue life test (T 0739-2011) originated from AASHTO T 321-03. The standard loading waveform of the fatigue test is a deviated sinusoidal wave. The testing temperature is $15^{\circ} \mathrm{C}$, the loading frequency is $10 \mathrm{~Hz}$, and the control strain is $400 \mu \varepsilon$.

The pavement performance of the HMRAM with three RAP contents and four types of DOB for each RAP content was tested. To ensure the accuracy of the test results, four parallel performance tests were conducted for each DOB. To minimize the variation in test results, a data snooping method based on a Gaussian distribution was used to detect and remove the outliers.

(1) Calculate the mean $\mu$ and standard deviation $\sigma$ using the following equations:

$$
\begin{aligned}
& \mu=\frac{1}{n} \sum_{i=1}^{n} R_{i}, \\
& \sigma=\sqrt{\sum_{i=1}^{n} \frac{\left(R_{i}-\mu\right)^{2}}{(n-1)}},
\end{aligned}
$$

where $R_{i}$ is the testing value of pavement performance; and $n$ is the sample size;

(2) Assume $R_{i}$ obeys the Gaussian distribution with mean $\mu$ and standard deviation $\sigma$ :

$$
R_{i} \sim N\left(\mu, \sigma^{2}\right)
$$

(3) Test whether or not the value of $R_{i}$ is an outlier by statistic test. The threshold for testing the outliers is set at $1.281 \sigma$, i.e., $80 \%$ of measurements within the range of $\mu \pm 1.281 \sigma$ :

$$
R>\mu \pm 1.281 \sigma \text { (consider outlier). }
$$


TABle 11: Composition of mastic.

\begin{tabular}{lcccccc}
\hline RAP content (\%) & DOB (\%) & Activated RAP binder (\%) & Virgin binder (\%) & Rejuvenator (\%) & Mineral filler (\%) & Total free binder (\%) \\
\hline & 100 & $1.32 / 1.76 / 2.20$ & $3.01 / 2.55 / 2.09$ & $0.07 / 0.09 / 0.11$ & $5.33 / 5.19 / 4.98$ & $4.40 / 4.40 / 4.40$ \\
$30 / 40 / 50$ & 90 & $1.19 / 1.58 / 1.98$ & $3.01 / 2.55 / 2.09$ & $0.07 / 0.09 / 0.11$ & $5.33 / 5.19 / 4.98$ & $4.27 / 4.22 / 4.18$ \\
& 80 & $1.06 / 1.41 / 1.76$ & $3.01 / 2.55 / 2.09$ & $0.07 / 0.09 / 0.11$ & $5.33 / 5.19 / 4.98$ & $4.14 / 4.05 / 3.96$ \\
& 70 & $0.92 / 1.23 / 1.54$ & $3.01 / 2.55 / 2.09$ & $0.07 / 0.09 / 0.11$ & $5.33 / 5.19 / 4.98$ & $4.00 / 3.87 / 3.74$ \\
\hline
\end{tabular}

Note. The " $"$ " is used to separate the values of each composition of mastic at $30 \%, 40 \%$, and $50 \%$ RAP content.

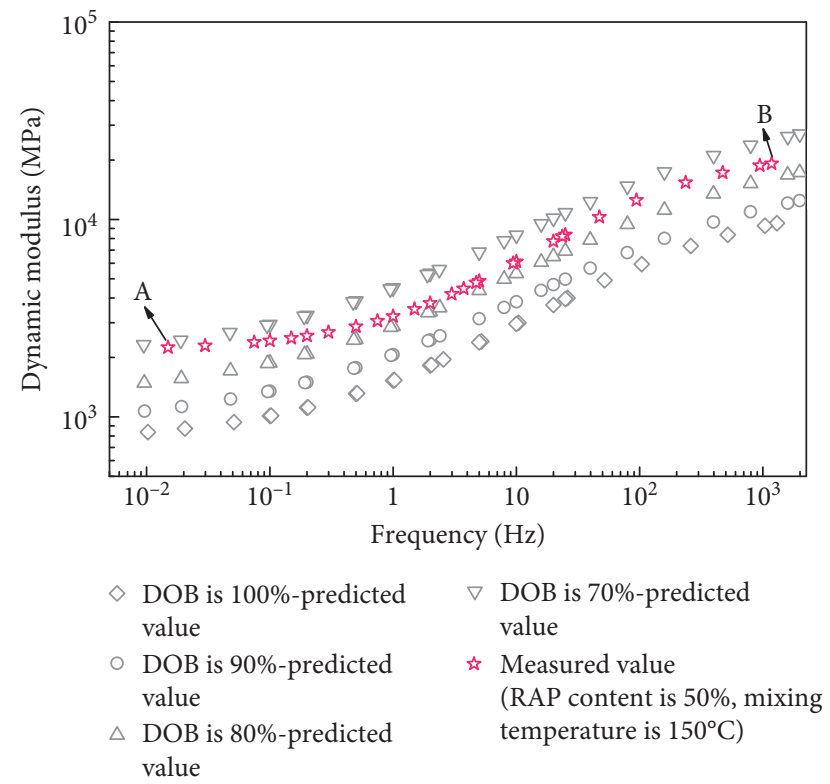

Figure 3: Prediction and measured dynamic different modulus master curve.

TABLE 12: Different DOB under four mixing methods.

\begin{tabular}{lcccc}
\hline $\begin{array}{l}\text { RAP } \\
\text { content } \\
(\%)\end{array}$ & $\begin{array}{c}\text { Mixing at } \\
150^{\circ} \mathrm{C}(\%)\end{array}$ & $\begin{array}{c}\text { Mixing at } \\
165^{\circ} \mathrm{C}(\%)\end{array}$ & $\begin{array}{c}\text { Mixing at } \\
180^{\circ} \mathrm{C}(\%)\end{array}$ & $\begin{array}{c}\text { Complete } \\
\text { blending }(\%)\end{array}$ \\
\hline 30 & 85.5 & 92.5 & 95.0 & 100 \\
40 & 80.5 & 86.0 & 87.5 & 100 \\
50 & 74.5 & 77 & 80.5 & 100 \\
\hline
\end{tabular}

The dynamic stability data of HMRAM with $40 \%$ RAP content under a mixing temperature of $150^{\circ} \mathrm{C}$ is taken as an example to illustrate the data snooping method. The four parallel test results are 3621 passes $/ \mathrm{mm}, 3598$ passes $/ \mathrm{mm}, 3665$ passes $/ \mathrm{mm}$, and 3752 passes $/ \mathrm{mm}$. The mean value $\mu$ is 3659 passes $/ \mathrm{mm}$, and $\sigma$ is 59 passes $/ \mathrm{mm}$. The range of $\mu \pm 1.281 \sigma$ is from 3584 passes $/ \mathrm{mm}$ to 3734 passes $/ \mathrm{mm}$. As the data point of 3752 passes $/ \mathrm{mm}$ falls outside of the range, it is removed.

\section{Results and Discussion}

3.1. DOB Results of HMRAM. As shown in Table 11, the DOBs are between $85.5 \sim 95 \%, 80.5 \sim 87.5 \%$, and $74.5 \sim 80.5 \%$ at the three mixing temperatures for HMRAM with 30, 40, and $50 \%$ RAP contents, which is inconsistent with the assumption of complete blending in the China specification. However, increasing the mixing temperature can significantly increase the DOB. For HMRAM with $30 \%$ RAP, the DOB is only $85.5 \%$ at a mixing temperature of $150^{\circ} \mathrm{C}$. However, the $\mathrm{DOB}$ is increased to $95 \%$ at $180^{\circ} \mathrm{C}$, where a complete blending state is nearly achieved. When the RAP content is $40 \%$ and $50 \%$, even with increasing the mixing temperature to $180^{\circ} \mathrm{C}$, the $\mathrm{DOB}$ can only reach $87.5 \%$ and $80.5 \%$, respectively, which is still that of a partial blending state. This conclusion is consistent with the research results of Coffey [18]. Therefore, the current specifications for HMRAM design are not suitable to use. In conclusion, the design method of HMRAM with high RAP content $(>30 \%)$ should be improved. The influence of the $\mathrm{DOB}$ on the effective asphalt content and pavement performance of the mixtures should be fully considered.

Since the increasing the mixing temperature can result in increased DOB, the mobilization of the aged binder coated outside the old aggregate may require more thermal energy and the increase of the mixing temperature can supply more thermal energy. Rad et al. proposed that temperature is the most important factor affecting the diffusion rate, and the development of mixing degree depends on the diffusion rate. The higher the temperature is, the faster the diffusion rate is, resulting in higher DOB [21]. The studies of Kriz et al. [20] and Bowers [22] also show that the increase in mixing temperature increases the DOB. This conclusion is also validated in this paper. However, it should be noted that a simple increase in the mixing temperature might cause excessive aging of the mixture, which negatively affects the pavement performance of HMRAM.

3.2. Effect of DOB on the Composition of the Total Free Binder. In this study, the total binder content of HMRAM with three RAP contents is $4.4 \%$, and the gradation is the same; therefore, the change in the total free binder content and properties due to different DOB becomes the important reason affecting the pavement performance of HMRAM. Two situations are considered to analyze the impact of DOB on the total free binder composition. One situation has the DOB remaining unchanged and RAP content changing; the other situation has the RAP content remaining unchanged and the DOB changing.

3.2.1. DOB Remains Unchanged and RAP Content Changes. The example of DOB equaling $85 \%$ and the RAP content changing from $30 \%$ to $50 \%$ is taken to illustrate the impact of this change. When the RAP content is $30 \%$, according to equation (1), the content of the activated RAP binder, 
virgin binder, and rejuvenator are $1.12 \%, 3.01 \%$, and $0.066 \%$, respectively. The total free binder content is $4.20 \%$.

When DOB is $100 \%$, the RAP binder can be completely converted to $\mathrm{AH}-70$ binder by adding the rejuvenator. However, when DOB is less than $100 \%$, the activated RAP binder decreases; adding the original amount of rejuvenator in this case results in the addition of too much rejuvenator, which will make the total free binder become softer. Thus, the rejuvenator is divided into two parts. One is named the balanced rejuvenator. The balanced rejuvenator is defined as the amount of the rejuvenator that can make the activated RAP binder exactly reach the requirements of the AH-70 binder. The other part is named excess rejuvenator, that is, the amount of the total rejuvenator minus the balanced rejuvenator, which makes the total free binder become softer.

In this example, the total rejuvenator is $0.066 \%$, the activated RAP binder is $1.12 \%$, the balanced rejuvenator is $0.056 \%(1.12 \% \times 5 \%, 5 \%$ is the dosage of the rejuvenator to make RAP binder reach the requirements of the AH-70 binder), and the excess rejuvenator is $0.010 \%(0.066 \%$ minus $0.056 \%$ ). When the RAP content is $40 \%$ and $50 \%$, the composition and content of the binder can be calculated using the same method. The calculation results are shown in Table 13.

According to the table above, when the RAP content decreases from $50 \%$ to $30 \%$, the total free binder content increases from $4.07 \%$ to $4.20 \%$, while the excess rejuvenator content decreases from $0.017 \%$ to $0.010 \%$. With the decrease in excess rejuvenator content, the free binder with a $30 \%$ RAP content is stiffer than that with a 50\% RAP content under the same DOB.

3.2.2. RAP Content Remains Unchanged and DOB Changes. HMRAM with a $30 \%$ RAP content is taken as an example for analysis. The composition and content of the binder under different DOBs is calculated and shown in the Table 14.

According to the above table, when DOB decreases from $100 \%$ to $70 \%$, the total free binder content decreases from $4.40 \%$ to $4.00 \%$, while the excess rejuvenator content increases from $0.00 \%$ to $0.02 \%$. The increase in the excess rejuvenator content makes the free binder at $100 \%$ DOB is stiffer than that at $70 \%$ DOB.

Voids in the mineral aggregate (VMA) and voids filled with asphalt (VFA) are important volume parameters of asphalt mixture. VMA is numerically equal to the air void content plus the effective binder content by volume. VFA is the percentage of VMA filled with asphalt binder [28]. Therefore, the higher the VMA and VFA in the mixture, the higher the effective binder content in the mixture. To verify whether the effective binder in mixtures increases with DOB, the VMA and VFA of HMRAM specimens with different mixing methods are tested. The volume of effective binder is also calculated according to the test results of VMA and VFA. The relationship between VMA, VFA, and effective binder volume and DOB is shown in Figure 4 .
The figure shows that the VMA and VFA of HMRAM specimens increase with $\mathrm{DOB}$, irrespective of the RAP content, even if it is $30 \%, 40 \%$, or $50 \%$. The volume of the effective binder calculated based on VMA and VFA also increases with DOB. Considering 50\% RAP content as an example, when DOB increases from $74.5 \%$ to $100 \%$, the volume of the effective binder also increases from $9.8 \%$ to $10.5 \%$. Such results further verify that when DOB increases, more RAP binders are converted to free binders, which leads to an increase in the volume of free binders in HMRAM. The properties of free binder also change.

\subsection{Pavement Performance of the HMRAM}

3.3.1. Effect of RAP Content and Mixing Temperature on the Pavement Performance. This paper considers the influence of RAP content and mixing temperature on the pavement performance of HMRAM. For each pavement performance indicator, there are four repeated tests for each combination of the two influence factors. We use variance of analysis (ANOVA) with dual-factor repeated test method to determine the significance of the two factors. The results of the calculation are shown in Table 15. According to the ANOVA results in Table 15, for the four pavement performance indicators, the mixing temperature and RAP content have a significant impact, which is consistent with the results of previous studies $[12,13]$.

\subsubsection{Effect of $D O B$ on the Pavement Performance}

(1) Data Statistics and Analysis Methods. For the three different RAP contents, the corresponding mean pavement performance value after removing outliers to different DOBs is shown in Figure 5. The relationship between $\mathrm{DOB}$ and pavement performance is fitted into a curve for the same RAP content. The 95\% confidence interval of the fitting curve is also used to determine whether each data point is within the confidence interval. If the point falls outside the interval, it is removed. Taking Figure 3 as an example, the $95 \%$ confidence interval of the fitting curve shows that the point with a DOB of $81 \%$ is within the $95 \%$ confidence interval. Therefore, this point cannot be removed, even though this data point appears to be an outlier.

To determine whether the slopes of the fitting curves between DOB and pavement performance are considerably different, we use a covariance analysis (ANCOVA). When the sig. value is less than 0.05 , the slopes of two fitting curves are considerably different. The relationship curves between $\mathrm{DOB}$ and pavement performance under three RAP contents and ANCOVA results are shown in Figure 6 and Table 16.

(2) High-Temperature Performance. From Figure 6(a), the dynamic stability (DS) decreases with the increase of the DOB for HMRAM. With the same DOB, the DS of HMRAM with a high RAP content is relatively high. For different RAP contents, the decline slope of fitting curve for $30 \%$ RAP content appears 
TABle 13: Composition of binder in HMRAM with 85\% DOB content.

\begin{tabular}{lcccccccc}
\hline $\begin{array}{l}\text { RAP } \\
\text { content (\%) }\end{array}$ & $\begin{array}{c}\text { Total binder } \\
\text { content (\%) }\end{array}$ & RAP binder (\%) & Rejuvenator (\%) & $\begin{array}{c}\text { Virgin } \\
\text { binder (\%) }\end{array}$ & $\begin{array}{c}\text { Activated RAP } \\
\text { binder (\%) }\end{array}$ & $\begin{array}{c}\text { Total free } \\
\text { binder (\%) }\end{array}$ & $\begin{array}{c}\text { Balanced } \\
\text { rejuvenator (\%) }\end{array}$ & $\begin{array}{c}\text { Excess } \\
\text { rejuvenator (\%) }\end{array}$ \\
\hline 30 & 4.40 & 1.32 & 0.066 & 3.01 & 1.12 & 4.20 & 0.056 & 0.010 \\
40 & 4.40 & 1.76 & 0.088 & 2.55 & 1.50 & 4.14 & 0.075 & 0.013 \\
50 & 4.40 & 2.20 & 0.110 & 2.09 & 1.87 & 4.07 & 0.094 & 0.017 \\
\hline
\end{tabular}

TABLE 14: Composition of binder in HMRAM with 30\% RAP content.

\begin{tabular}{lcccccccc}
\hline DOB (\%) & $\begin{array}{c}\text { Total binder } \\
\text { content (\%) }\end{array}$ & $\begin{array}{c}\text { RAP } \\
\text { binder (\%) }\end{array}$ & Rejuvenator (\%) & $\begin{array}{c}\text { Virgin } \\
\text { binder (\%) }\end{array}$ & $\begin{array}{c}\text { Activated RAP } \\
\text { binder (\%) }\end{array}$ & $\begin{array}{c}\text { Total free } \\
\text { binder (\%) }\end{array}$ & $\begin{array}{c}\text { Balanced } \\
\text { rejuvenator (\%) }\end{array}$ & $\begin{array}{c}\text { Excess } \\
\text { rejuvenator (\%) }\end{array}$ \\
\hline 70 & 4.40 & 1.32 & 0.066 & 3.01 & 0.92 & 4.00 & 0.046 & 0.020 \\
80 & 4.40 & 1.32 & 0.066 & 3.01 & 1.06 & 4.14 & 0.053 & 0.013 \\
90 & 4.40 & 1.32 & 0.066 & 3.01 & 1.19 & 4.27 & 0.059 & 0.007 \\
100 & 4.40 & 1.32 & 0.066 & 3.01 & 1.32 & 4.40 & 0.066 & 0.000 \\
\hline
\end{tabular}

to be considerably less than that of $40 \%$ and $50 \%$ RAP content. The statistical analysis results listed in Table 16 indicate that the curve slope of $30 \%$ and $50 \%$ RAP content is considerably different. This indicates that the change of DOB has an even greater effect on the DS of HMRAM with high RAP content, as compared to HMRAM with a low RAP content.

According to the variation trend of high-temperature performance of HMRAM with DOB, it can be inferred that a higher DS presented by HMRAM with a high RAP content is not necessarily safe at the design stage because the DOB will gradually increase after construction based on Carpenter and Wolosick [14]; thus, its DS value will also gradually decrease. The final high-temperature performance may not meet the requirements. Therefore, it is suggested that an HMRAM specimen with a complete blending state be used to measure the high-temperature performance for HMRAM with a high RAP content. HMRAM can be prepared by mixing the virgin binder and aggregate with a completely separating RAP binder and old aggregate using the RAP extraction method.

We try to analyze the reasons why DOB affects hightemperature performance of HMRAM based on the change of content and properties of free binder in HMRAM. According to the results in Section 3.2, when DOB increases, more RAP binders are converted to free binders, which leads to an increase of total free binder in HMRAM. The properties of free binder are also change. It may be the important reason affecting the pavement performance of HMRAM.

The example of HMRAM with a $30 \%$ RAP content showed in Table 14 is discussed. With the DOB increasing from $70 \%$ to $100 \%$, the total free binder content increases from $4.00 \%$ to $4.40 \%$, while the excess rejuvenator content decreases from $0.02 \%$ to $0.00 \%$. Figure 6 (a) shows that the increase of total free binder content will increase VMA and binder film thickness. Recent research (documented in NCHRP Report 567) suggests that rut resistance of asphalt concrete mixtures decreases with increasing VMA and apparent film thickness. Therefore, the high-temperature performance will decrease with the total free asphalt. The reduction in the excess rejuvenator content makes the free binder at $70 \%$ DOB softer than that at $100 \%$ DOB. In general, the softening of asphalt binder will reduce the high-temperature performance of mixtures. Therefore, the changes in the total free binder content and properties have the opposite effects on the high-temperature performance of HMRAM. The results shown in Figure 6(a) indicate that the increase of total free binder has a great impact.

When DOB remains unchanged and RAP content changes, the example of $85 \%$ DOB showed in Table 12 is discussed. The RAP content decreases from $50 \%$ to $30 \%$, the total free binder content increases from $4.07 \%$ to $4.2 \%$, while the excess rejuvenator content decreases from $0.017 \%$ to $0.010 \%$. Similar to the analysis above, the changes in the total free binder content and properties also have the opposite effects on high-temperature performance of HMRAM. The change of total free binder has a greater impact based on Figure 6(a).

When the DOB approaches $100 \%$, the DS values of HMRAM with three RAP contents are nearly similar, based on Table 17 and Figure 6(a). The other three pavement performance indicators present similar trends. We use variance of analysis (ANOVA) to determine the significance of effect of the RAP content on high-temperature performance under $100 \%$ DOB. The results of the calculation are shown in Table 18. It presents statistical significant difference for the pavement performance of HMRAM with different RAP contents under $100 \% \mathrm{DOB}$, especially for fatigue performance.

In this study, the HMRAM specimens with $100 \%$ DOB are prepared by mixing the virgin binder and aggregate with a complete separating RAP binder and old aggregate using the RAP extraction method. The RAP binder coated outside the old aggregate is extracted completely and uniformly mixed with virgin binder and rejuvenator; therefore, avoiding the heterogeneous binder across the mixture. For HMRAM with different RAP contents, the gradation of aggregates, the properties and the content of mixed binder 


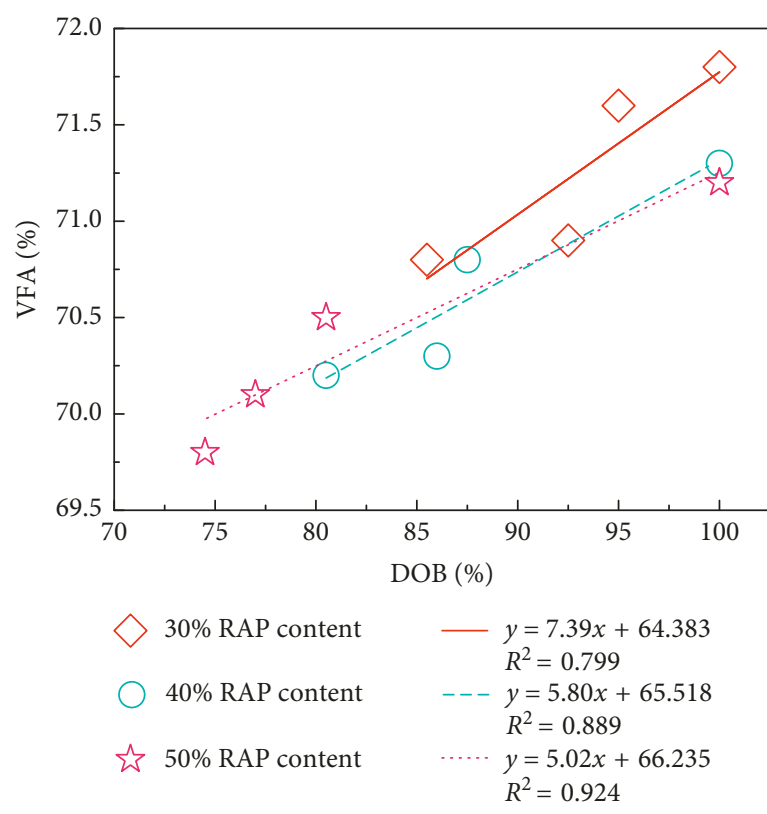

(a)
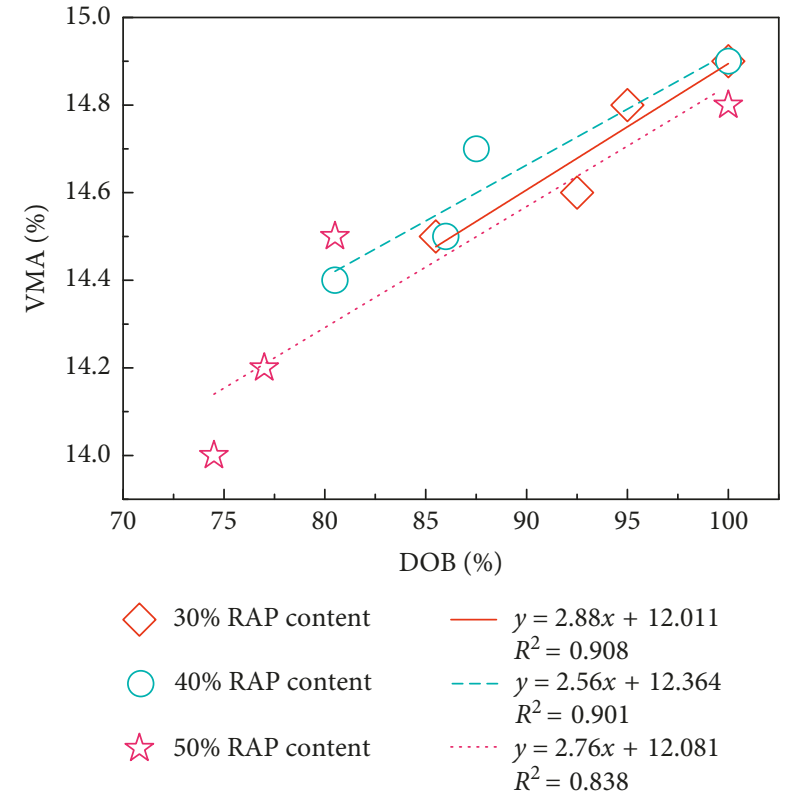

(b)

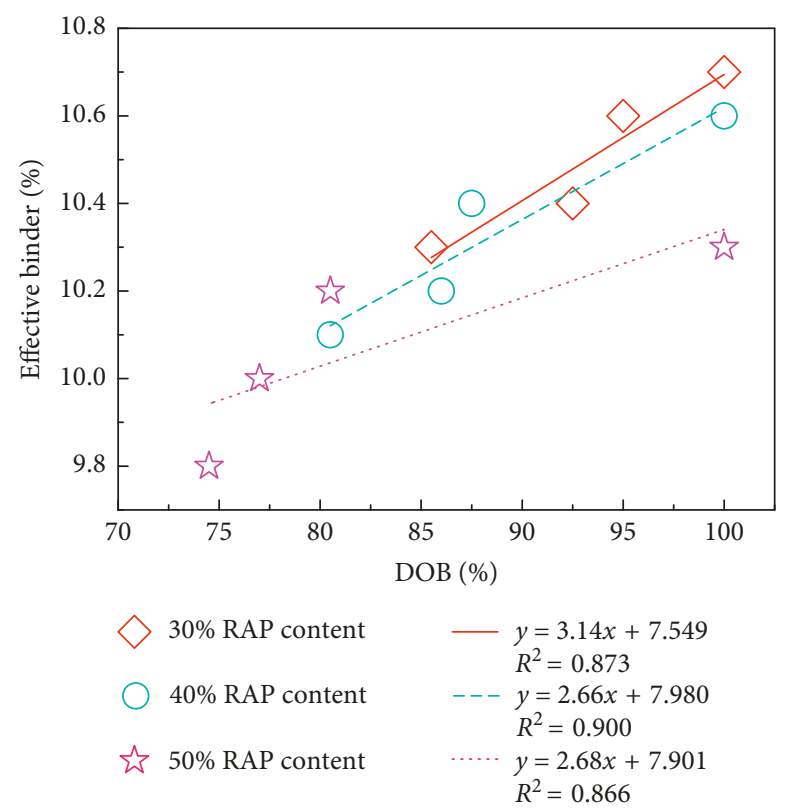

(c)

FIgure 4: The relationship between VMA, VFA, and effective binder volume and DOB.

TABLE 15: Results of ANOVA with dual-factor repeated test $(\alpha=0.05)$.

\begin{tabular}{lccccc}
\hline Pavement performance & Factors & $F$ & $F_{\text {crit }}$ & $F$ vs. $F_{\text {crit }}$ & Results \\
\hline \multirow{2}{*}{ Dynamic stability } & Mixing temperature & 224.07 & 3.35 & $F>F_{\text {crit }}$ & Significance \\
& RAP content & 2221.46 & 3.35 & $F>F_{\text {crit }}$ & Significance \\
\hline \multirow{2}{*}{ TSR } & Mixing temperature & 234.06 & 3.35 & $F>F_{\text {crit }}$ & Significance \\
& RAP content & 2082.01 & 3.35 & $F>F_{\text {crit }}$ & Significance \\
\multirow{2}{*}{ Flexural failure strain } & Mixing temperature & 13.31 & 3.35 & $F>F_{\text {crit }}$ & Significance \\
& RAP content & 178.37 & 3.35 & $F>F_{\text {crit }}$ & Significance \\
\multirow{2}{*}{ Fatigue life } & Mixing temperature & 25277.95 & 3.35 & $F>F_{\text {crit }}$ & Significance \\
& RAP content & 2591114.44 & 3.35 & $F>F_{\text {crit }}$ & Significance \\
\hline
\end{tabular}




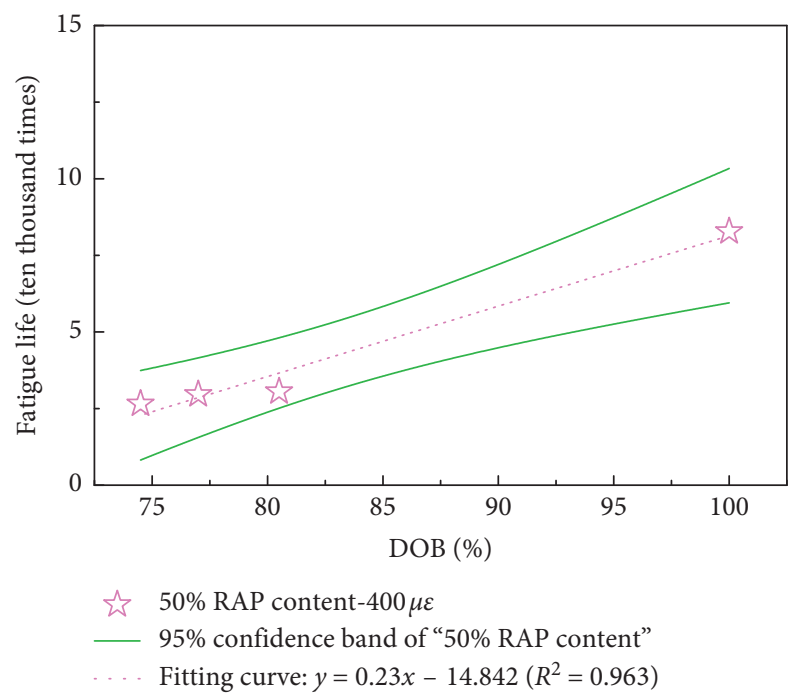

Figure 5: Confidence interval of the fitting curve between DOB and pavement performance.

are all the same. The only difference is the proportion of the old aggregate. No RAP binder is coated outside the old aggregate at this time after extraction. Regarding the old aggregate, its physical properties such as angularity, and strength deteriorate with an increase in service periods. Its properties are also different from those of virgin aggregate used in this research. The crushing value and Los Angeles wear loss of old aggregates are worse than those of virgin aggregates, as indicated in Tables 2 and 5. Therefore, when the content of old aggregates varies considerably for HMRAM with different RAP contents, it may slightly influence the performance of HMRAM. However, the rules of influence do not have to be further studied in the future.

(3) Moisture Stability, Low-Temperature Performance, and Fatigue Performance. Figures 6(b)-6(d) show the similar effects of $\mathrm{DOB}$ on moisture stability, low-temperature performance, and fatigue performance. The three performance indicators increase with an increase in the DOB for HMRAM with the same RAP content and decrease with an increase in the RAP content for HMRAM with the same DOB. If the moisture stability, low-temperature performance, and fatigue performance of HMRAM meets the requirements of specification at the design stage, there is no risk that these pavement performances of HMRAM will decrease with an increase in DOB after construction. Therefore, the moisture stability, low-temperature performance, and fatigue resistance performance of HMRAM measured at the design stage is reasonable and conservative.

As for different RAP contents, the statistical analysis results listed in Table 18 indicate that the curve slopes of $30 \%$ and 50\% RAP blending rates are significantly different. The change of DOB has a greater impact on moisture stability, low-temperature performance, and fatigue performance of
HMRAM with a high RAP content than that with a low RAP content.

When DOB or RAP content changes, the content and properties of the total free binder in HMRAM are also important factors affecting moisture stability, low-temperature performance, and fatigue performance. Considering the fatigue performance as an example, recent research (documented in NCHRP Report 567) suggests that the primary HMA mixture design factor affecting fatigue life is the effective volumetric binder content of the mixture (VBE). For a given pavement, fatigue life increases with VBE. Considering 50\% RAP content as an example, when DOB increases from $74.5 \%$ to $100 \%$, total free binder increases. The VBE increased from $9.8 \%$ to $10.5 \%$. Although the total free binder is stiffer, the fatigue life of HMRAM increases significantly from 26,534 times to 82,751 times. However, as analyzed in the previous section, we cannot ignore the influence of the difference of the ratio of RAP aggregate on the fatigue performance of HMRAM with different RAP contents.

According to recent studies, when partial blending status is observed between RAP binder and virgin binder, the distribution of total free binder in the blending zone is heterogeneous (Figure 7). The free binder near RAP aggregate is stiffer and that far from RAP aggregate is softer. In this paper, we suggest that the content of total free asphalt will vary with DOB by calculating and measuring the changes of VMA, VFA, and VBE. We also infer that the increasing content of aged RAP binder with DOB results in hardening of total free binder. However, this is only a qualitative explanation for the whole properties of total free binder. In fact, the specific effect of the heterogeneous distribution of free binder on HMRAM with partial blending state is very complex, and further research is required. Simultaneously, when the RAP content is different, the physical properties of the old aggregate such as 


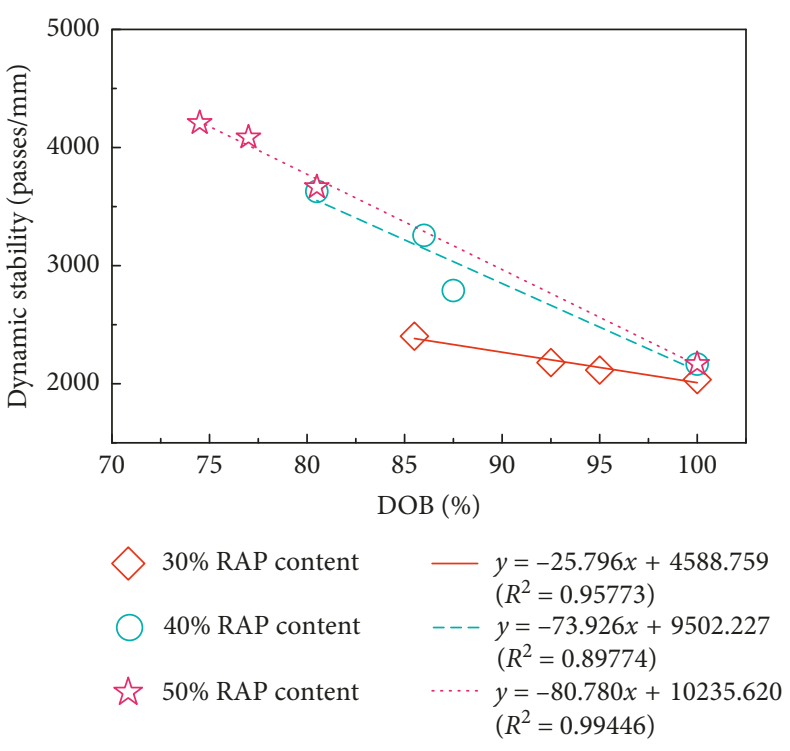

(a)

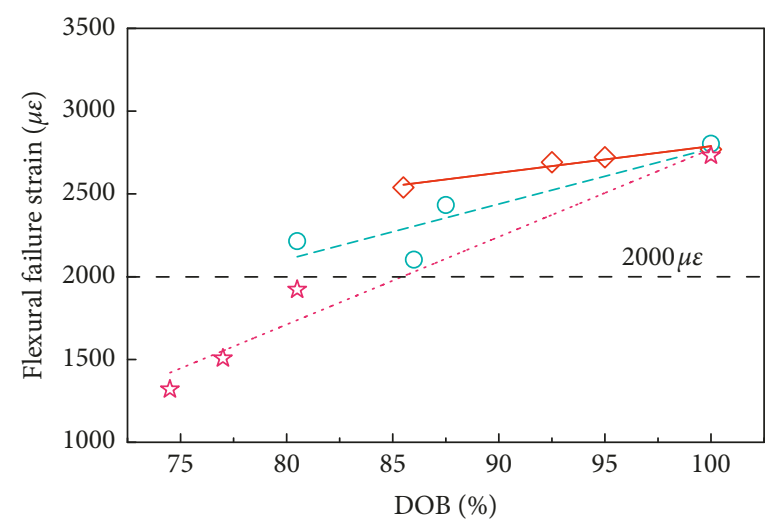

$$
\begin{aligned}
& >30 \% \text { RAP content }-y=16.08 x+1180.318 \\
& \left(R^{2}=0.9317\right) \\
& \text { 40\% RAP content - - - } y=33.53 x-579.186 \\
& \left(R^{2}=0.7027\right) \\
& \text { ¿ } 50 \% \text { RAP content } \quad \cdots \cdots \quad y=52.98 x-2527.002 \\
& \left(R^{2}=0.9396\right)
\end{aligned}
$$

(c)

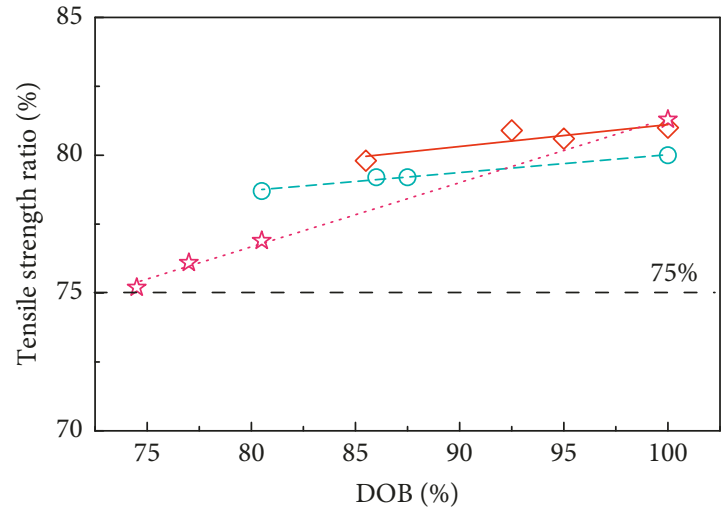

$$
\begin{aligned}
& \diamond 30 \% \text { RAP content }-y=0.079 x+73.170 \\
& \left(R^{2}=0.6642\right) \\
& \text { 40\% RAP content --- } y=0.065 x+73.534 \\
& \text { 放 50\% RAP content …... } y=0.233 x+58.029 \\
& \left(R^{2}=0.9955\right)
\end{aligned}
$$

(b)

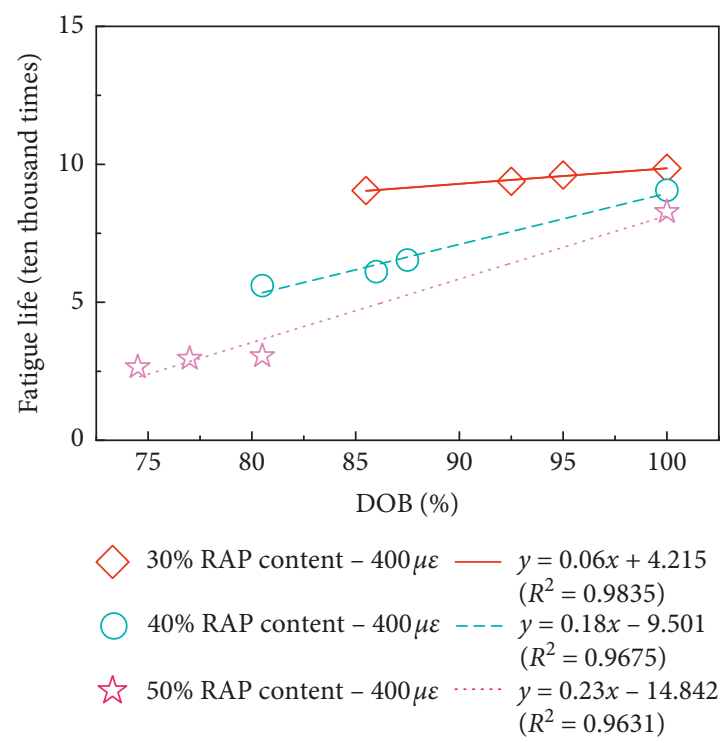

(d)

FIGURE 6: Influences of the DOB on the pavement performance. (a) Dynamic stability; (b) moisture stability; (c) low-temperature performance; (d) fatigue performance.

TABLE 16: ANCOVA results of slope difference for different RAP contents.

\begin{tabular}{lccr}
\hline Pavement performance & & RAP contents \\
& $30 \%$ vs. $40 \%$ & $40 \%$ vs. $50 \%$ & $30 \%$ vs. $50 \%$ \\
\hline Dynamic stability & 0.048 (Sig.) & 0.626 & 0.001 (Sig.) \\
TSR & 0.621 & 0.000 (Sig.) & 0.005 (Sig.) \\
Flexural failure strain & 0.289 & 0.233 & 0.036 (Sig.) \\
Fatigue life & 0.006 (Sig.) & 0.273 & 0.012 (Sig.) \\
\hline
\end{tabular}

TABLE 17: Mean value of pavement performance under 100\% DOB.

\begin{tabular}{lcccc}
\hline RAP content $(\%)$ & Dynamic stability (passes/mm) & TSR $(\%)$ & Flexural failure strain $(\mu \varepsilon)$ & Fatigue life (times) \\
\hline 30 & 2035 & 81.0 & 2769 & 98564 \\
40 & 2166 & 80.0 & 2803 & 90568 \\
50 & 2168 & 81.3 & 2732 & 82751 \\
\hline
\end{tabular}


TABle 18: Results of ANOVA $(\alpha=0.05)$.

\begin{tabular}{lccccc}
\hline Pavement performance & Factors & $F$ & $F_{\text {crit }}$ & $F$ vs. $F_{\text {crit }}$ & Results \\
\hline Dynamic stability & RAP content & 24.99 & 4.26 & $F>F_{\text {crit }}$ & Significance \\
TSR & RAP content & 25.27 & 4.26 & $F>F_{\text {crit }}$ & Significance \\
Flexural failure strain & RAP content & 7.06 & 4.26 & $F>F_{\text {crit }}$ & Significance \\
Fatigue life & RAP content & 1314.87 & 4.26 & $F>F_{\text {crit }}$ & Significance \\
\hline
\end{tabular}

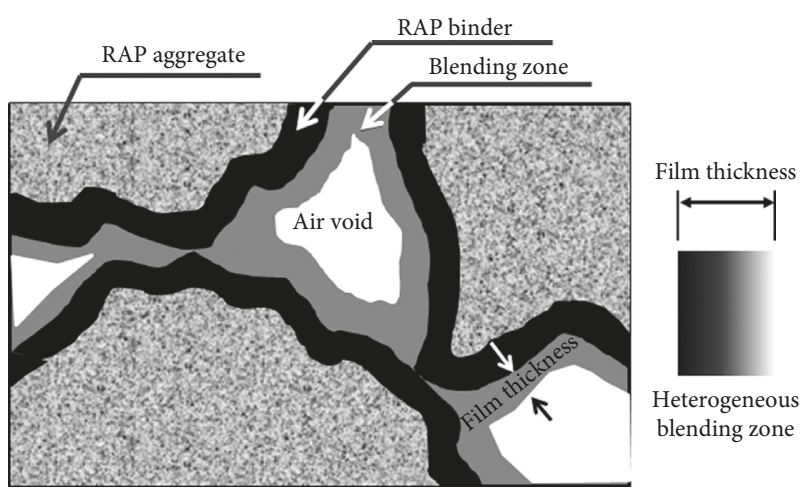

Figure 7: Microstructure of heterogeneous blending zone.

angularity and strength, are also different from those of the virgin aggregate. Therefore, its content will also have a significant impact on the performance of HMRAM.

\section{Conclusions and Recommendations}

In this study, the influence of the DOB between the virgin and aged binder on high-temperature, low-temperature, moisture stability, and fatigue resistance performance of HMRAM with different high RAP contents and mixing methods are investigated. The main conclusions are summarized as follows:

(1) The DOBs are between $85.5 \sim 95 \%, 80.5 \sim 87.5 \%$, and $74.5 \sim 80.5 \%$ at the three mixing temperatures for HMRAM with 30, 40, and 50\%, which is inconsistent with the assumption of a complete blending state in the China specification. The current specifications for the HMRAM design are unsuitable for usage. Therefore, it is necessary to adjust the mixing process and determine the DOB between the virgin binder and RAP binder according to the method proposed in this study. Then, on the premise of avoiding secondary aging, the optimal mixing process should be determined based on the maximum DOB.

(2) The dynamic stability of the mixture gradually decreases with the increase of the DOB for HMRAM with a high RAP content, while the moisture stability, low-temperature, and fatigue resistance performance are continuously improved. Therefore, it is suggested that HMRAM with a complete blending state be used to measure the high-temperature performance. The moisture stability, low-temperature performance, and fatigue resistance performance of HMRAM measured at the design stage is reasonable and conservative.
(3) With the change in the DOB between the virgin binder and RAP binder, the content and properties for the total free binder in HMRAM are the important factors affecting pavement performance. The content and physical properties of the RAP aggregate such as angularity and strength also have a significant impact on the performance of HMRAM.

The following improvements for this study should be made in the future. Only HMRAM with 30\%, 40\%, and 50\% RAP contents are discussed in this paper, which corresponds to a gradation of AC-16. More types of mixture with a higher RAP content should be studied. A simpler design method of HMRAM should be proposed in the future. The specific effect of the heterogeneous distribution of free binder on HMRAM with partial blending state is very complex, and further research is needed. The content and physical properties of old aggregate in RAP materials may have an important influence on pavement performance of HMRAM with a high RAP content. Related research is also needed in the future.

\section{Data Availability}

The data used to support the findings of this study areavailable from the corresponding author upon request.

\section{Conflicts of Interest}

The authors declare no conflicts of interest.

\section{Acknowledgments}

This research was funded by the Science and Technology Project of Beijing Education Commission (SQKM201810016003) and the Fundamental Research Project of Universities Affiliated to Beijing Education Commission (FZ01-48).

\section{References}

[1] H. Song-Chang, P. Ming-Wen, and J. Xu, "Application of asphalt pavement recycling technology at home and abroad," Highway Transportation Technology, vol. 2006, no. 11, pp. 5-8, 2006.

[2] I. L. Al-Qadi, M. Elseifi, and S. H. Carpenter, "Reclaimed asphalt pavement-a literature review," Tech. Report No. FHWA-ICT-07-001, Illinois Department of Transportation, Springfield, IL, USA, 2007.

[3] B. Huang, G. Li, D. Vukosavljevic, X. Shu, and B. Egan, "Laboratory investigation of mixing hot-mix asphalt with reclaimed asphalt pavement," Transportation Research 
Record: Journal of the Transportation Research Board, vol. 1929, no. 1, pp. 37-45, 2005.

[4] B. F. Bowers, B. Huang, Q. He, X. Shu, X. Jia, and B. C. Miller, "Investigation of sequential dissolution of asphalt binder in common solvents by FTIR and binder fractionation," Journal of Materials in Civil Engineering, vol. 27, no. 8, Article ID 04014233, 2015.

[5] S. Zhao, B. Huang, X. Shu, and M. E. Woods, "Quantitative evaluation of blending and diffusion in high RAP and RAS mixtures," Materials \& Design, vol. 89, pp. 1161-1170, 2016.

[6] I. L. Al-Qadi, S. H. Carpenter, G. Roberts et al., "Determination of usable residual asphalt binder in RAP," Research Report ICT-R27-11, Illinois Center for Transportation, Rantoul, IL, USA, 2009.

[7] T. Bennert and R. Dongré, "Backcalculation method to determine effective asphalt binder properties of recycled asphalt pavement mixtures," Transportation Research Record: Journal of the Transportation Research Board, vol. 2179, no. 1, pp. 75-84, 2010.

[8] S. Parashant, Y. A. Mehta, and A. Nolan, "A study to determine the degree of partial blending of reclaimed asphalt pavement (RAP) binder for high RAP hot mix asphalt," in Proceeding of the transportation research board, 89th annual meeting, Washington, DC, USA, January 2010.

[9] R. Bonaquist, "Laboratory evaluation of hot mix asphalt (HMA) mixtures containing recycled or waste product materials using performance testing," Report FHWA-PA-2005006+98-32(19), Pennsylvania Department of Transportation, Harrisburg, PA, USA, 2005.

[10] A. Shah, R. S. McDaniel, G. Huber, and V. Gallivan, "Investigation of properties of plant-produced RAP mixtures," Journal of the Transportation Research Board: Journal of the Transportation Research Board, vol. 1998, no. 1, pp. 103-111, 2007.

[11] G. R. Kemp and N. H. Predoehl, "A comparison of field and laboratory environments on asphalt durability," in Proceedings of the Association of Asphalt Paving Technologists, vol. 50, pp. 492-537, San Diego, CA, USA, 1981.

[12] I. L. Al-QadiS. H. Carpenter et al., "Determination of usable residual asphalt binder in RAP," Report No. FHWA-ICT-09031, Illinois Department of Transportation, Springfield, IL, USA, 2009.

[13] Q. Aurangzeb, I. L. Al-Qadi, I. M. Abuawad, W. J. Pine, and J. S. Trepanier, "Achieving desired volumetric and performance for high RAP mixtures," in Proceedings of the TRB Annual Meeting, Washington, DC, USA, January 2012.

[14] S. H. Carpenter and J. R. Wolosick, "Modifier Influence in the Characterization of Hot-Mix Recycled Material," pp. 15-22, Transportation Research Board, Washington, DC, USA, 1980.

[15] A. S. Noureldin and L. E. Wood, "Rejuvenator diffusion in binder film for hot-mix recycled asphalt pavement," in Transportation Research Record: Journal of the Transportation Research Board, pp. 51-61, no. 1115, Transportation Research Board of National Academies, Washington, DC, 1987.

[16] R. S. McDaniel, H. Soleymani, R. M. Anderson, P. Turner, and R. Peterson, "Recommended use of reclaimed asphalt pavement in the superpave mixture design method," NCHRP Final Report (9-12), TRB, Washington, DC, USA, 2000.

[17] J. E. Stephens, J. Mahoney, and C. Dippold, "Determination of the PG binder grade to use in a RAP mix," Report No. JHR 00278, Connecticut Department of Transportation, Newington, CT, USA, 2001.

[18] S. Coffey, E. Dubois, Y. A. Mehta, and C. Purdy, "Determining impact of blending between virginand reclaimed asphalt binder on predicted pavement performance using mechanistic-empirical pavement design guide," in Proceedings of the 92nd annual meeting compendium of papers, p. 17, Transportation research board, Washington, DC, USA, January 2013.

[19] K. Zhang and B. Muhunthan, "Effects of production stages on blending and mechanical properties of asphalt mixtures with reclaimed asphalt pavement," Construction and Building Materials, vol. 149, pp. 679-689, 2017.

[20] P. Kriz, D. L. Grant, B. A. Gale et al., "Blending and diffusion of reclaimed asphalt pavement and virgin asphalt binders," Road Materials and Pavement Design, vol. 15, no. 1, pp. 78112, 2014.

[21] F. Y. Rad, N. R. Sefidmazgi, and H. Bahia, "Application of diffusion mechanism," Transportation Research Record: Journal of the Transportation Research Board, vol. 2444, no. 1, pp. 71-77, 2014.

[22] F. B. Bowers, "Investigation of asphalt pavement mixture blending utilizing analytical chemistry techniques," Doctoral Dissertations University of Tennessee, Knoxville, Tenn, USA, 2013.

[23] B. Huang, X. Shu, and D. Vukosavljevic, "Laboratory investigation of cracking resistance of hot-mix asphalt field mixtures containing screened reclaimed asphalt pavement," Journal of Materials in Civil Engineering, vol. 23, no. 11, pp. 1535-1543, 2011.

[24] X. Shu, B. Huang, E. D. Shrum, and X. Jia, "Laboratory evaluation of moisture susceptibility of foamed warm mix asphalt containing high percentages of RAP," Construction and Building Materials, vol. 35, pp. 125-130, 2012.

[25] S. Zhao, B. Huang, X. Shu, X. Jia, and M. Woods, "Comparative evaluation of warm mix asphalt containing high percentages of reclaimed asphalt pavement," Construction and Building Materials, vol. 44, pp. 92-100, 2013.

[26] R. Karlsson and U. Isacsson, "Laboratory studies of diffusion in bitumen using markers," Journal of Materials Science, vol. 38, no. 13, pp. 2835-2844, 2003.

[27] C. Zhang, S. Shen, and X. Jia, "Modification of the Hirsch dynamic modulus prediction model for asphalt mixtures," Journal of Materials in Civil Engineering, vol. 29, no. 12, Article ID 04017241, 2017.

[28] National Academies of Sciences, Engineering, and medicine, "A Manual for Design of Hot-Mix Asphalt with Commentary," The National Academies Press, Washington, DC, USA, 2011.

[29] S. N. Nahar, M. Mohajeri, A. J. M. Schmets, A. Scarpas, M. F. C. van de Ven, and G. Schitter, "First observation of the blending zone morphology at the interface of reclaimed asphalt binder and virgin bitumen," Transportation Research Record Journal of the Transportation Research Board, vol. 2370, no. 1, pp. 1-9, 2013. 


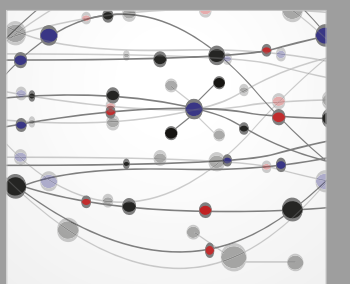

The Scientific World Journal
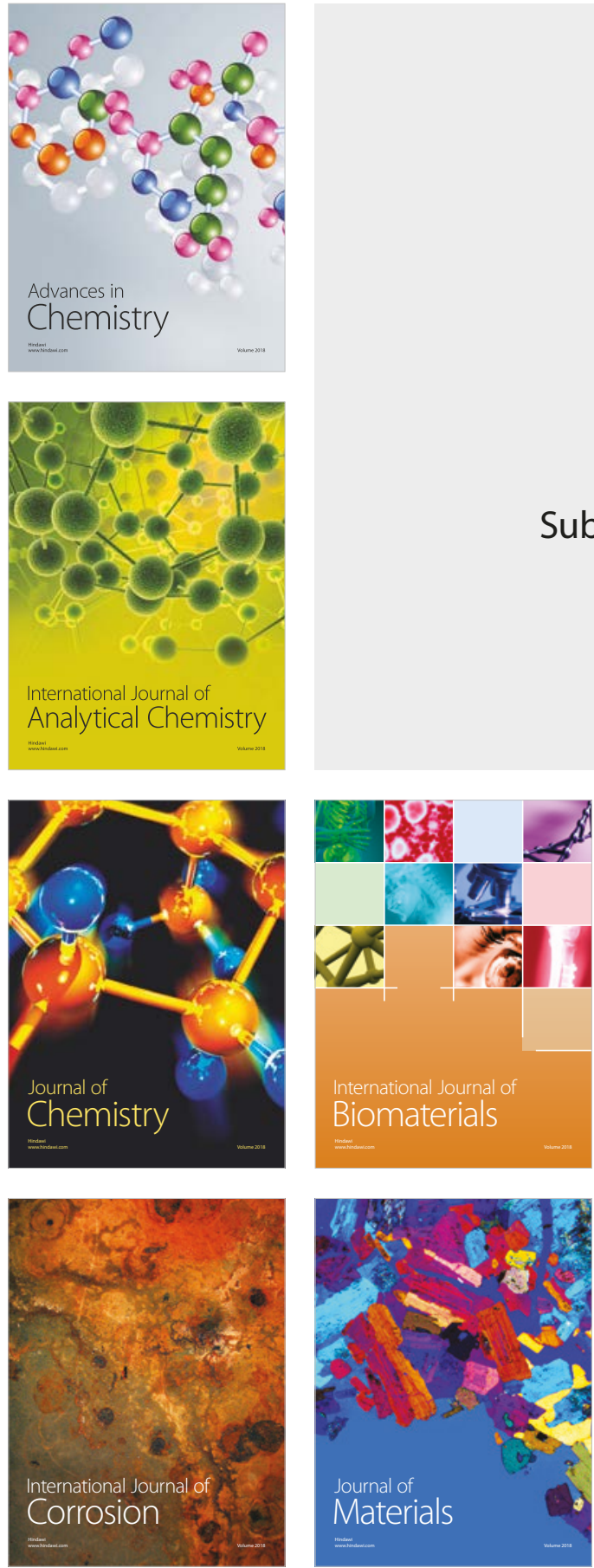

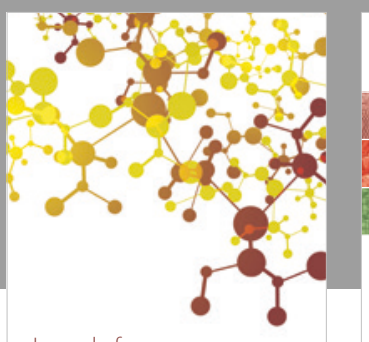

Journal of

Applied Chemistry
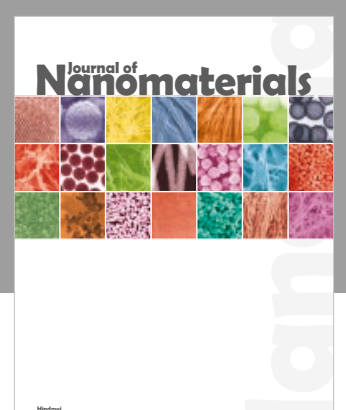

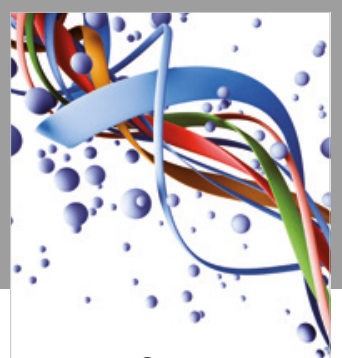

Scientifica

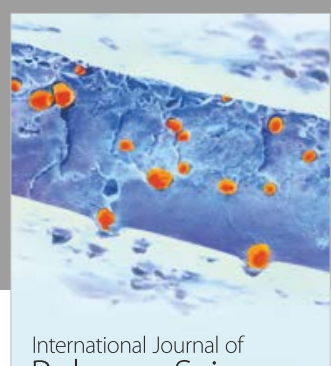

Polymer Science

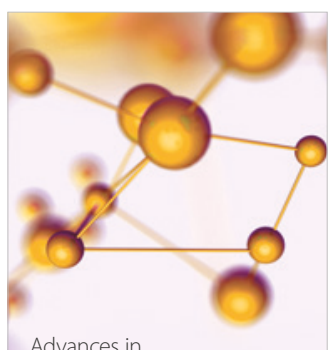

Physical Chemistry
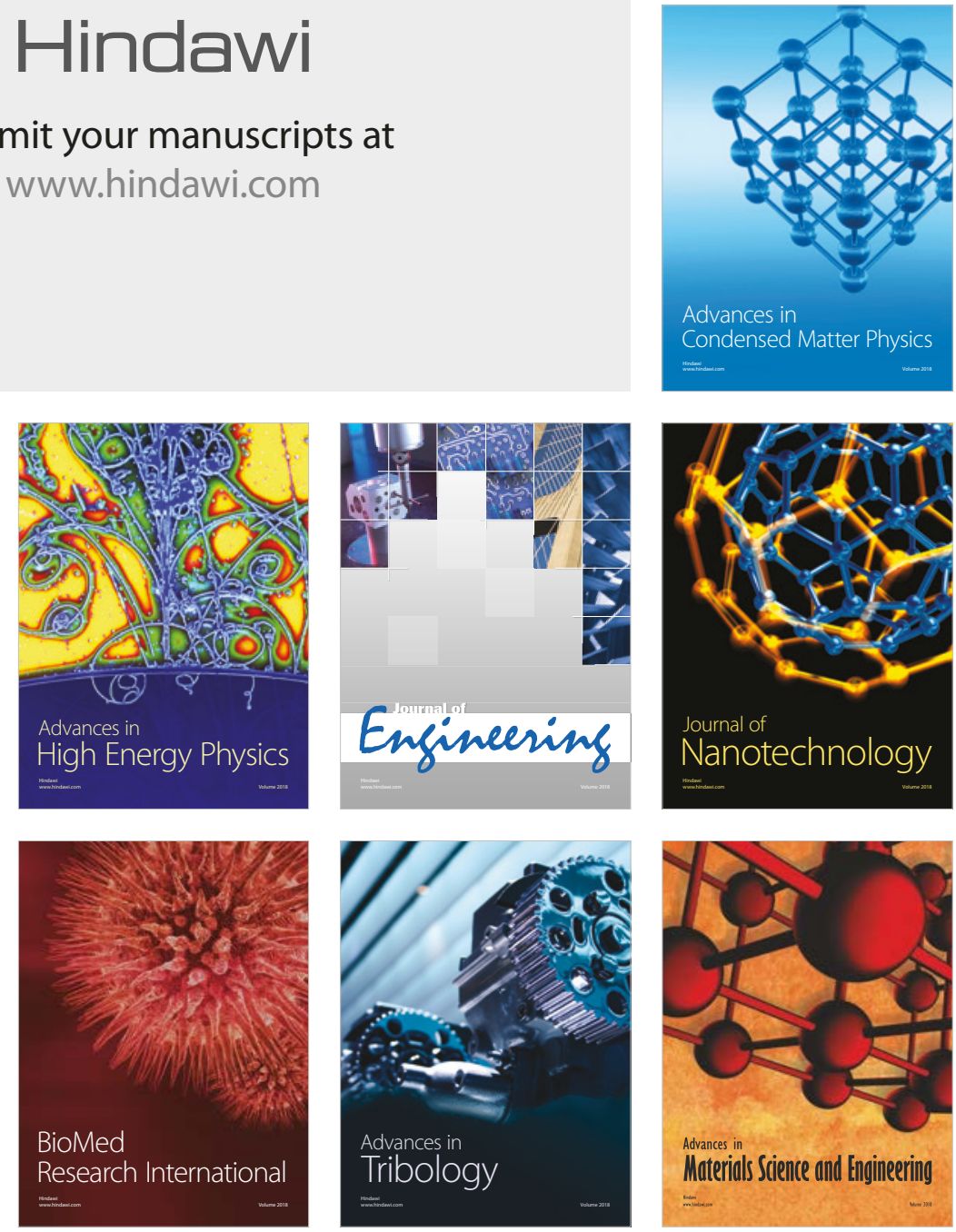